\title{
Two Gln187 mutants of human soluble APRIL inhibit proliferation of lung carcinoma A549 cells
}

\author{
Shuangshuang Dai ${ }^{1 \#}$, Yingru Zheng ${ }^{2 \#}$, Bin Chen $^{1}$, Min Gao $^{1}$, Yan Zhang1, Li Zhang ${ }^{1}$, \\ Wei Gong ${ }^{1}$ and Fengtain $\mathrm{He}^{1 凶}$ \\ ${ }^{1}$ Department of Biochemistry and Molecular Biology, Third Military Medical University; and ${ }^{2}$ Department of \\ Obstetrics \& Gynecology, Research Institute of Surgery, Third Military Medical University, Chongqing, China
}

Received: 19 August, 2009; revised: 01 December, 2009; accepted: 06 December, 2009

avaialble on-line: 07 December, 2009

\begin{abstract}
Soluble APRIL (sAPRIL), the active form of a proliferation-inducing ligand (APRIL), is implicated in the proliferation of tumor cells. Suppressing APRIL function has been considered as a potential strategy for the therapy of APRIL-associated tumors. In the present study, we generated human sAPRIL and its two mutants, Gln187-D-sAPRIL (Gln187 deleted) and Gly187-sAPRIL (GIn187 replaced by Gly). In vitro experiments showed that the two mutants had similar specific binding capacity to lung carcinoma A549 cells compared to the wild-type sAPRIL, and both, especially Gly187-sAPRIL, exhibited significant antagonistic effect on sAPRIL-induced tumor cell proliferation in a dose-dependent manner, which might be predominantly mediated by blocking SAPRIL-induced MEK and ERK phosphorylation but not p38MAPK or JNK signaling. In vivo experiments with nude mice bearing A549 cell-derived xenograft tumor showed that only the Gly187-sAPRIL mutant could significantly suppress the tumor growth. These results suggest that Gln187 may be a crucial amino acid in APRIL-mediated tumor cell proliferation via the MEKERK signaling pathway and that the SAPRIL mutants may serve as novel potential antagonists of

APRIL for the therapy of APRIL-associated cancers.
\end{abstract}

Keywords: APRIL, Gln187 mutant of sAPRIL, anti-tumor activity

\section{INTRODUCTION}

A proliferation-inducing ligand (APRIL), so named after its inducing effect on tumor cell proliferation, is a member of tumor necrosis factor (TNF) family (Hahne et al., 1998; Medema et al., 2003), which is converted in the Golgi apparatus by furin convertase, resulting in its secretion as soluble APRIL (sAPRIL, 105-250 amino acids) (López-Fraga et al., 2001). sAPRIL triggers subsequent intracellular activity and acts as a homotrimer after bind- ing its receptors including $B$ cell maturation antigen (BCMA), transmembrane activator and calcium signal-modulating cyclophilin ligand interactor (TACI), as well as heparin sulfate proteoglycans (HSPGs) (Marsters et al., 2000; Kalled et al., 2005; Ingold et al., 2005). The mRNA and protein levels of APRIL or sAPRIL are reported to be low in normal tissues but much higher in a variety of tumor cells and tissues, such as gastrointestinal tumors, lung carcinomas, and melanoma (Hahne et al., 1998; Stein et al., 2002; Roth et al., 2001). Patients with certain B-cell

${ }^{\square}$ Corresponding author: Fengtian He, Department of Biochemistry and Molecular Biology, Third Military Medical University, 30 Gaotanyan, Shapingba, Chongqing 400038, China; phone/fax: 86(23) 6875 2262, e-mail: hefengtian06@yahoo. com.cn

\#These authors contributed equally to this work.

GenBank: Accession number: human APRIL, BAE16556.1; human BAFF(Blys), AAQ89240.1

Abbreviations: APRIL, A proliferation-inducing ligand; sAPRIL, soluble APRIL; BAFF, B-cell activation factor belonging to the TNF family; BCMA, B cell maturation antigen; BSA, bovine serum albumin; FBS, fetal bovine serum; HSPG, Heparan sulphate proteoglycan; MAPK, mitogen-activated protein kinase; TACI, transmembrane activator and calcium signal-modulating cyclophilin ligand interactor; TNF, tumor necrosis factor. 
lymphomas, multiple myelomas, or brain glioblastomas are also reported to exhibit serum values of sAPRIL significantly higher than those detected in normal donors, and a retrospective clinical analysis also found a significant correlation between high expression of APRIL in tumor lesions and decreased overall patient survival rates (Iłzecka \& Iłzecki, 2006; Planelles et al., 2007; Schwaller et al., 2007). Additionally, recent studies have demonstrated that APRIL promotes solid tumor development in an autocrine fashion (Rennert et al., 2000; Bonci et al., 2004; Roosnek et al., 2009). Therefore, suppressing APRIL function may be a potential strategy for the therapy of APRIL-associated tumors.

The available researches have shown that a soluble form of APRIL's receptor BCMA (sBCMA$\mathrm{Fc}$ ) retards tumor growth in vivo. But as we know, BCMA, as well as TACI, are also receptors of another TNF family member, B-cell activation factor (BAFF) (Rennert et al., 2000). So using the soluble forms of the two receptors as antagonists of APRIL to inhibit tumor cell growth may also interfere with the function of BAFF. This consideration led us to inquire into a novel strategy to develop potential antagonists of APRIL to inhibit tumor cell proliferation.

APRIL is most homologous to another TNF family ligand BAFF, which is also called TALL-1 (Yu et al., 2000; Rennert et al., 2000). A previous study has demonstrated that a mutant of human BAFF in which eight amino acid residues (aa217-224) are replaced with two glycines has a similar binding capacity to BAFF receptors as wild-type BAFF, but it fails to activate the receptors and to promote B lymphocyte proliferation (Liu et al., 2006). Based on the BLAST alignment of the two proteins (as shown in Fig. 1) and the work of Wallweber et al. (2004), both indicating that aa187-188 of APRIL may functionally correspond to aa217-224 of BAFF, we presumed that mutation of aa187-188 of APRIL may block APRILinduced tumor cell proliferation. Because residue 188 is a Gly in native APRIL, we targeted only residue 187 (Gln) by either deleting it (mutant Gln187-DsAPRIL) or replacing it with a Gly (mutant Gly187sAPRIL), which means aa187-188 were replaced with one or two Glys. Subsequently, their binding capaci-

\begin{tabular}{cccccc} 
& \multicolumn{4}{c}{187} & 188 \\
hAPRIL & 172 & QDVTFTMGQVVSREGQ & $\ldots .$. & GRQETLFRCIRSMP & 201 \\
hBAFF & 202 & TDKTYAMQHLIQRKKVHVFGDELSLVTLFRCIQNMP & 237 \\
& & & 217 & 224 &
\end{tabular}

Figure 1. Sequence alignment of human APRIL and human BAFF. Amino-acids sequence of APRIL (GenBank BAE16556.1) and BAFF (GenBank AAQ89240.1) were alined and the targets of mutation in APRIL were chosen by protein-protein BLAST as previously described (Wallweber et al., 2004). APRIL aa 187-188 and corresponding BAFF aa 217-224 are marked in red. Residues forming the receptor binding-site are marked in green. The mutation site is outside the receptor binding region. ties to lung carcinoma A549 cells and effects on tumor proliferation in vitro and in vivo were analyzed.

\section{MATERIALS AND METHODS}

Cell culture and animals. The human lung carcinoma cell line A549 was obtained from American Type Culture Collection and cultured in DMEM supplemented with $10 \%$ FBS (Hyclone, USA), streptomycin $(100 \mu \mathrm{g} / \mathrm{mL})$, penicillin $(100 \mathrm{U} / \mathrm{mL})$, and $2 \mathrm{mM}$ glutamine. Male nude mice, 5-6 weeks old and weighing 18-23 g, were purchased from Vital River Experimental Animals Co. Ltd. (Beijing, China) and housed in the Experimental Animals Center of the Third Military Medical University (Chongqing, China).

Synthesis of proteins for SAPRIL and its mutants. Using the total RNA extracted from human tonsil tissue as the template, human sAPRIL cDNA (encoding aa 105-250) was amplified by RT-PCR with the oligonucleotides 5'-GCGGGTACCGCAGTGCTCACCCAAAAACA-3' (forward primer) and 5'-GCGAAGCTTTCACAGTTTCACAAACCCCA-3' (reverse primer), and cloned into vector pUC19 after being digested with KpnI and HindIII. Using this recombinant plasmid as the template, the two kinds of mutants of sAPRIL targeting Gln187 were constructed by a one-step opposite-direction PCR with TaKaRa MutanBest Kit (TaKaRa, Japan) according to the manufacturer's protocol. The primers for the mutant Gln187-D-sAPRILwere 5'-GAAGGCGGAAGGCAGGAGACT-3' (forward primer) and 5'-TCGAGACACCACCTGACCCAT-3' (reverse primer), and the primers for the mutant Gly187-sAPRIL were 5'-GAAG(forward primer) and 5'-TCGAGACACCACCTGACCCAT-3' (reverse primer). The DNA fragments of wild-type sAPRIL and its two mutants digested with KpnI and HindIII were inserted into pQE-80L with $6 \times$ His-tag and then expressed in Escherichia coli DH5 $\alpha$. The His-tagged sAPRIL, Gln187-D-sAPRIL and Gly187-sAPRIL were purified from the bacterial lysate by binding to $\mathrm{Ni}^{2+}-$ NTA agarose (Qiagen, USA) and eluted with 200 $\mathrm{mM}$ imidazole ( $\mathrm{pH}$ 5.9). After refolding by dialysis as previously described (Wingfield et al., 1995), homotrimers (functional forms) of SAPRIL and its two mutants were isolated using Sephacryl S-200 gel filtration chromatography separately. The purity of the proteins was further confirmed by $15 \%$ SDS/PAGE with Coomassie blue staining and Western blotting using mouse anti-His-tag antibody (Qiagen, USA) as described (Gao 
et al., 2006). Briefly, after separation by SDS/PAGE, the proteins were transferred to a nitrocellulose membrane and incubated with the primary and secondary antibodies. The immunoreactive bands were visualized using the ECL system.

Flow cytometry analysis. The binding activities of sAPRIL and its mutants to A549 cells were measured with mouse anti-His-tag antibody (Qiagen, USA) and FITC-conjugated goat anti-mouse IgG (Promega, USA) using a FACS Calibur analyzer with corrected mean fluorescence intensity and the binding affinity was scored by Fluorescence index (FI): high $(\mathrm{FI}>1.5)$, intermediate $(1.0<\mathrm{FI}<1.5)$, or weak (FI>0.5) (Nijman et al., 1993).

In vitro cell proliferation assay. A549 cells were arrested in G0/G1 phase by serum deprivation for $24 \mathrm{~h}$ and then administered with increasing doses $(0,0.01,0.1$ or $1 \mu \mathrm{g} / \mathrm{mL})$ of the three recombinant proteins alone or mixture of $1 \mu \mathrm{g} / \mathrm{mL}$ recombinant sAPRIL and various concentrations $(0,0.01,0.1$ or 1 $\mu \mathrm{g} / \mathrm{mL}$ ) of the mutants in DMEM supplemented with $2 \%$ FBS. After $48 \mathrm{~h}$, cells were pulsed with $1 \mu \mathrm{Ci}$ of $\left[{ }^{3} \mathrm{H}\right]$ thymidine for a further $8 \mathrm{~h}$ at $37^{\circ} \mathrm{C}$. The cells were incubated overnight with $10 \%$ trichloroacetic acid (TCA) at $4^{\circ} \mathrm{C}$, and incorporated $\left[{ }^{3} \mathrm{H}\right]$ thymidine was then extracted in $\mathrm{NaOH}$ and measured in a liquid scintillation counter (LS 6500, Beckman Instruments; Fullerton, CA, USA). To facilitate comparison between different conditions, absolute counts were converted to a percentage of control (untreated) counts. All values are means \pm S.E.M. of three independent experiments done in triplicate.

Signaling pathway analysis. Using Western blotting, we assayed phosphorylated p38 MAPK, JNK, MEK and ERK (p-p38, p-JNK, p-MEK, and p-ERK). Total MEK and ERK were also assayed to identify pMEK and p-ERK expressions. Briefly, after treatment with $1 \mu \mathrm{g} / \mathrm{mL}$ sAPRIL in the presence of various concentrations $(0.01,0.1$ or $1 \mu \mathrm{g} / \mathrm{mL})$ of the two mutants, total cellular extracts of A549 cells were separated on a 10\% SDS/PAGE gel and transferred to nitrocellulose membranes. Following blocking in TBS and Tween 20 (TBST; $10 \mathrm{mM}$ Tris/HCl, pH 7.5, $150 \mathrm{mM} \mathrm{NaCl}$, and $0.05 \%$ Tween 20 ) containing $10 \%$ nonfat instant milk powder, the nitrocellulose membranes were incubated overnight at $4^{\circ} \mathrm{C}$ with primary antibodies (1:1000 dilution of anti-phospho-p38, anti-phospho-JNK, anti-
phospho-MEK, anti-phospho-ERK, anti-total MEK or anti-total ERK antibodies; Cell Signaling, USA) in TBS containing 10\% milk. After washing with TBST and incubation with the secondary antibody, the immunoreactive bands were visualized employing an ECL detection system (GE, USA).

In vivo xenograft tumor growth assay. A549 cells were harvested, washed twice and resuspended in pyrogen-free PBS at $5 \times 10^{6}$ cells $/ \mathrm{mL}$. Mice were anesthetized using an i.p. injection of $100 \mathrm{mg} / \mathrm{kg}$ ketamine and $5 \mathrm{mg} / \mathrm{kg}$ xylazine. Then $200 \mu \mathrm{L}$ of A549 cells was carefully implanted subcutaneously in the flank abdominal area of the mice. Purified proteins were injected i.p. into the mice just before tumor cell implantation and every three days thereafter. The injected dose for both Gln187-D-sAPRIL and Gly187-sAPRIL was $1 \mathrm{mg} / \mathrm{kg}$, and the control group received PBS. Xenograft tumor diameter was measured on day 30 after implantation using a caliper, and tumor volume was calculated using the formula $\mathrm{v}=4 / 3 \pi \mathrm{R}^{3}$.

Statistical analysis. Graphic data were expressed as mean \pm S.E.M. Statistical analyses of the data were performed by Student's $t$-test and oneway ANOVA. $P<0.05$ was considered as a significant difference.

\section{RESULTS}

Recombinant sAPRIL and its two mutants. Recombinant human sAPRIL and its two mutants targeting Gln187 expressed in E. coli were purified by $\mathrm{Ni}^{2+}$-NTA agarose. After dialysis for refolding, all proteins were over $90 \%$ pure, and the molecular mass of each monomer was about $17 \mathrm{kDa}$, as revealed by Coomassie blue staining of SDS/PAGE (Fig. 2A). The proteins were further analyzed by Western blotting (Fig. 2B).

The two sAPRIL mutants had a similar binding capacity to A549 cells with the wild-type sAPRIL. Following preparation of the recombinant sAPRIL and its two mutants, we used flow cytometry analysis to detect their binding capacity to lung carcinoma A549 cells, with PBS as negative control. As shown in Fig. 3, all three recombinant proteins could bind to A549 cells with similar affinities at the middle level. In addition, no significant difference of FI was observed in them. These results indicated that the two kinds of mutations targeting Gln187 in sAPRIL do not substantially affect its binding capacity.
Figure 2. SDS/PAGE and Western blot analysis of purified sAPRIL and the two mutants.

(A) SDS/PAGE analysis. (B) Western blot analysis. The purified sAPRIL and its two mutants were about 17-kDa (monomers).
B

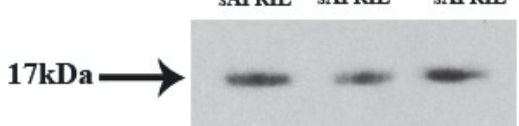


A

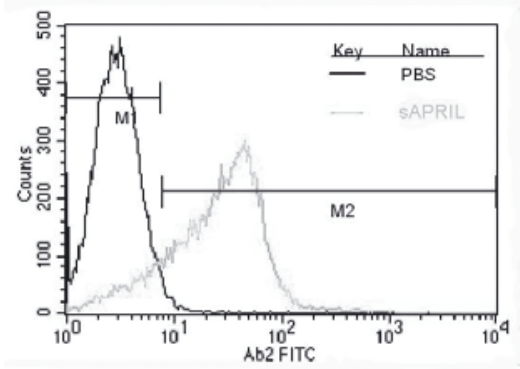

File: SAPRIL

Marker Events \% Gated \% Total Mean

$\begin{array}{rrrrr}\text { All } & 14502 & 100.00 & 97.87 & 36.80 \\ \text { M1 } & 2075 & 14.31 & 14.00 & 4.41\end{array}$

$\begin{array}{lllll}\text { M2 } & 12427 & 85.69 & 83.86 & 42.21\end{array}$

FI: 1.45

$$
\text { B }
$$
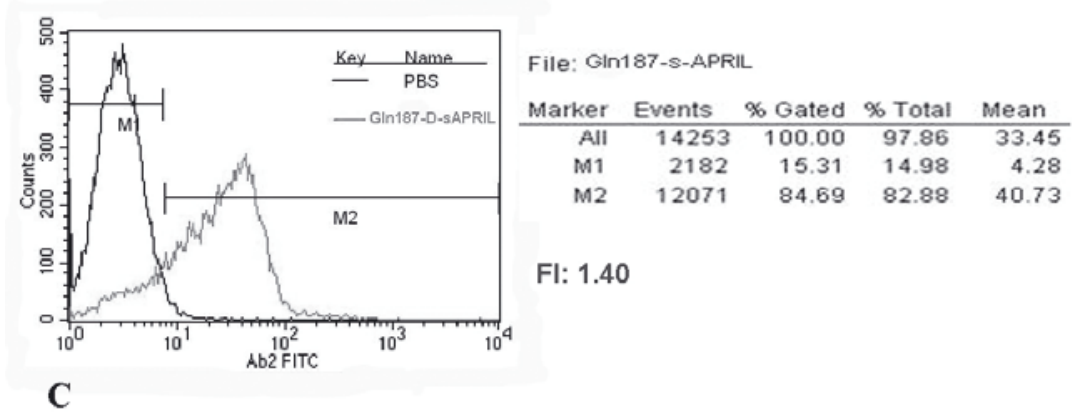

FI: 1.40
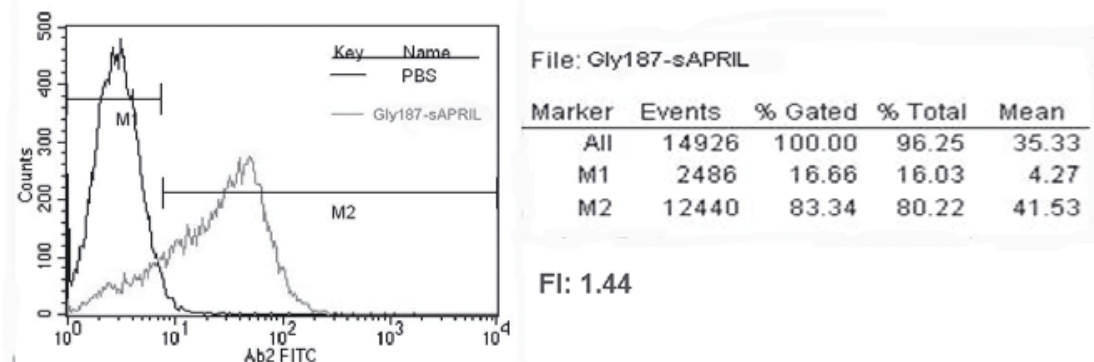

FI: 1.44
Figure 3. Binding of SAPRIL and its two mutants to A549 cells. The binding activities of sAPRIL and its mutants to A549 cells were measured by flow cytometry analysis. (A) sAPRIL binding to A549 cells. (B) Mutant Gln187D-sAPRIL binding to A549 cells. (C) Mutant Gly187-sAPRIL binding to A549 cells. PBS served as control.
Both mutants inhibit sAPRIL-induced A549 cell proliferation in vitro. To investigate whether the recombinant proteins affected tumor cell growth, we measured proliferation of A549 cells treated with either of the three proteins by the $\left[{ }^{3} \mathrm{H}\right]$ thymidine incorporation assay. As shown in Fig. 4A, sAPRIL alone promoted proliferation, but two mutants, especially Gly187-sAPRIL, inhibited proliferation of A549 cells in a dose-dependent manner.

In competitive experiments, A549 cells were challenged with $1 \mu \mathrm{g} / \mathrm{mL}$ sAPRIL in the presence of various concentrations of Gln187-D-sAPRIL or Gly187-sAPRIL. Gly187-sAPRIL could completely block the sAPRIL-induced cell proliferation (Fig. 4C), while Gln187-D-sAPRIL had only a partial blocking effect (Fig. 4B).

Inhibition of MEK/ERK signaling was involved in the mutant-mediated blocking of sAPRIL-induced A549 cell proliferation. To investigate the potential MAPK signaling pathway involved in the antagonism of sAPRIL by the mutants, p-p38, p-JNK, p-MEK, and p-ERK were assayed using Western blotting. As shown in Fig. 5, there were no significant changes of p-p38 or p-JNK in cells treated with sAPRIL alone or with $1 \mu \mathrm{g} /$ $\mathrm{mL}$ sAPRIL in the presence of different concentra- tions of the mutants. But as shown in Fig. 6A and Fig. 6B, sAPRIL treatment alone clearly increased pMEK level, which could be dramatically blocked by Gly187-sAPRIL in a dose-dependent manner (Fig. 6B) and partially blocked by Gln187-D-sAPRIL (Fig. 6A). MEK operates upstream of ERK1/2, so p-ERK was also determined at the same time points. The results showed that changes of $\mathrm{p}$-ERK1/2 paralleled those of p-MEK in cells treated with sAPRIL or its mutants (Fig. 6C and Fig. 6D). This result suggested that inhibition of APRIL-induced activation of MEK/ ERK signaling might be a mechanism of the mutantmediated blocking of sAPRIL-induced proliferation of A549 cancer cells.

Mutant Gly187-sAPRIL but not Gln187-DsAPRIL suppressed tumor growth in vivo. The demonstration that the two mutants can inhibit the sAPRIL-induced A549 cell proliferation in vitro prompted us to investigate whether they have an anti-tumor effect in vivo. The lung carcinoma cell line A549 was grown as subcutaneous tumors in nude mice and subjected to Gln187-D-sAPRIL or Gly187-sAPRIL treatment. As shown in Fig. 7, 30 days after tumor cell implantation, the xenograft tumor size for control group mice was $0.09-0.12 \mathrm{~cm}^{3}$, while treatment with Gly187-sAPRIL yielded a sig- 
$\mathbf{A}$

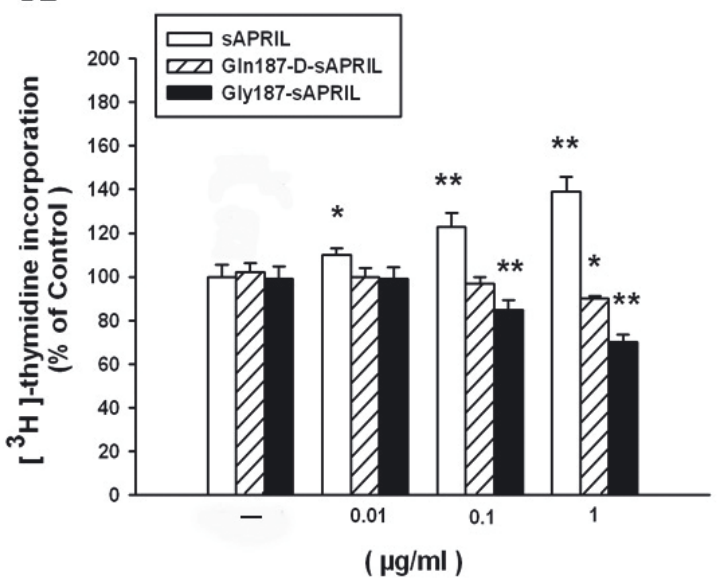

B

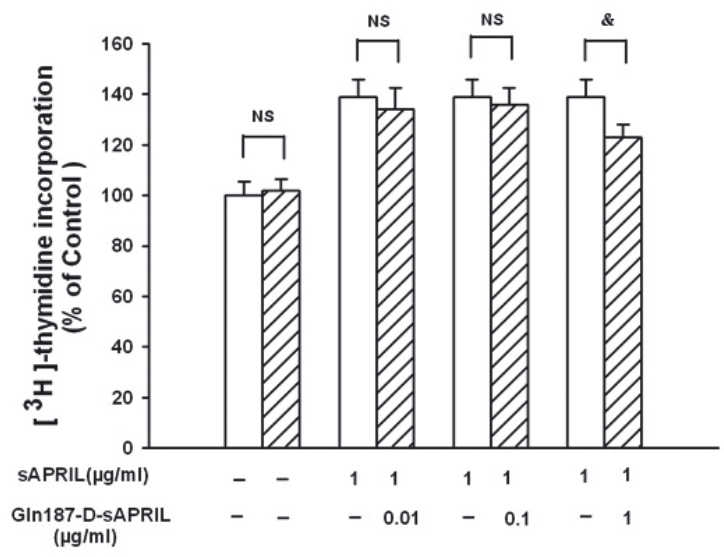

nificant reduction in tumor size to about $0.02-0.05$ $\mathrm{cm}^{3}(P<0.01)$. However, no such tumor growth retardation was observed in the nude mice with the administration of Gln187-D-sAPRIL (tumor size $\left.0.08-0.13 \mathrm{~cm}^{3}\right)$.

\section{DISCUSSION}

In the present study, we successfully generated two sAPRIL mutants targeting residue Gln187 with a similar specific binding capacity to lung carcinoma A549 cells as that of wild-type sAPRIL. Both mutants, especially Gly187-sAPRIL, inhibited A549 cell proliferation and exhibited antagonistic effects on SAPRIL-induced tumor cell proliferation in vitro, which might be mediated by blocking sAPRIL-induced MEK/ERK signaling. However, in vivo experiments indicated that only the Gly187-sAPRIL mutant significantly suppressed tumor growth in mice transplanted with A549 cells.

It has been reported that SAPRIL exerts its effect by binding to three receptors-BCMA, TACI and HSPG (Marsters et al., 2000; Kalled et al., 2005; Ingold et al., 2005). Our FACS analysis showed

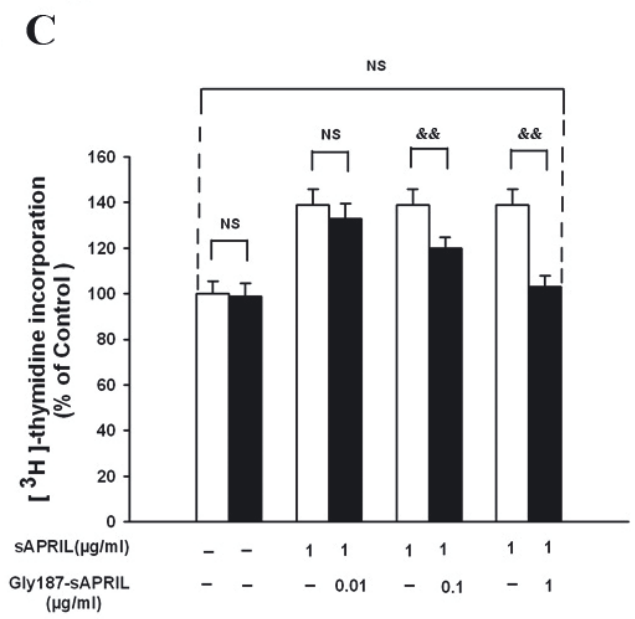

Figure 4. Antagonistic effects of sAPRIL mutants on APRIL-induced A549 cell proliferation.

Cells were incubated with various concentrations (0.01, 0.1 or $1 \mu \mathrm{g} / \mathrm{mL}$ ) of sAPRIL, Gln187-D-sAPRIL or Gly187sAPRIL alone (A) or treated with $1 \mu \mathrm{g} / \mathrm{mL}$ sAPRIL in the presence of various concentrations $(0.01,0.1$ or $1 \mu \mathrm{g} / \mathrm{mL}$ ) of Gln187-D-sAPRIL (B) or Gly187-sAPRIL (C). Then, the $\left[{ }^{3} \mathrm{H}\right]$ thymidine incorporation assay was performed to determine their effects on A549 cell proliferation. The values are ${ }^{3} \mathrm{H}$ incorporation (inc.) expressed as percentage of control and represent means of three independent experiments done in triplicate. ${ }^{*} P<0.05$ and ${ }^{* *} P<0.01$ compared to the control, $\& P<0.05$ and ${ }^{\&} \& P<0.01$ compared to the two indicated groups, NS: not significant.

that the two kinds of mutants targeting Gln187 of sAPRIL can bind to human lung carcinoma A549 cells as well as does wild-type sAPRIL. Since BCMA and TACI are heavily absent on A549 cells (Rennert et al., 2000) and previous research has found that HSPG binding promotes APRIL-induced tumor cell proliferation (Hendriks et al., 2005), it seems likely that HSPG expressed on A549 cells is responsible for the binding of recombinant sAPRIL and its mutants. Whether HSPG is the only receptor mediating the sAPRIL-induced tumor cell proliferation or some other receptor of APRIL take part in the response is not clear and requires further investigation. However, the deletion of Gln187 or its replacement with a Gly in sAPRIL had no effect on their specific binding to the receptors, indicating that Gln187 of sAPRIL is not necessary for its binding.

A549 cells express endogenous sAPRIL which can stimulate cell proliferation, a process called autocrine regulation (Rennert et al., 2000). In the cell proliferation assay, we found that the two mutants alone can retard cell proliferation in a dose-dependent manner. Because sAPRIL and its two mutants bind to A549 cells with similar efficiency, it seems likely that the two mutants may compete with endogenous sAPRIL for binding to the same receptors on A549 cells and antagonize sAPRIL-induced tumor cell proliferation. To confirm this hypothesis, we challenged 
A

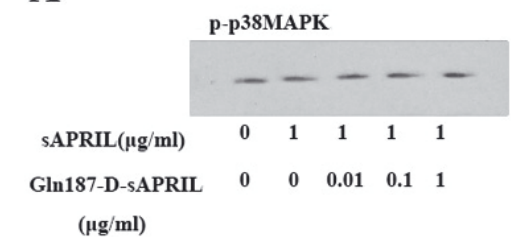

C

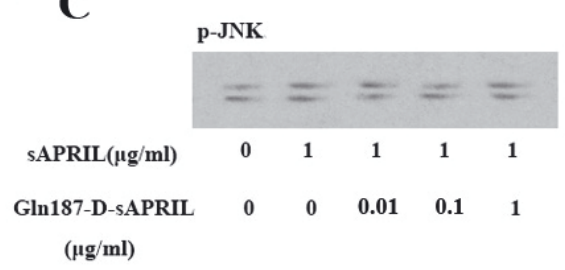

E

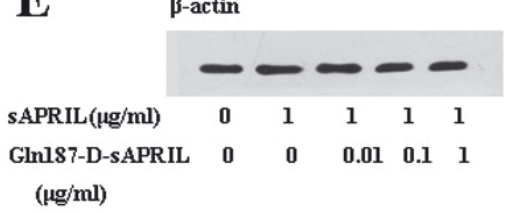

$\mathbf{A}$

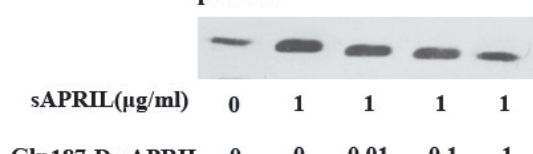

$(\mu \mathrm{g} / \mathrm{ml})$

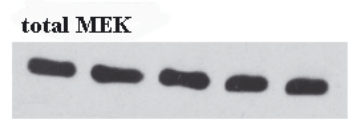

$\begin{array}{llllll}\operatorname{sAPRIL}(\mu \mathrm{g} / \mathrm{ml}) & 0 & 1 & 1 & 1 & 1\end{array}$

$\begin{array}{llllll}\text { Gln187-D-SAPRIL } & 0 & 0 & 0.01 & 0.1 & 1\end{array}$ $(\mu \mathrm{g} / \mathrm{ml})$

C

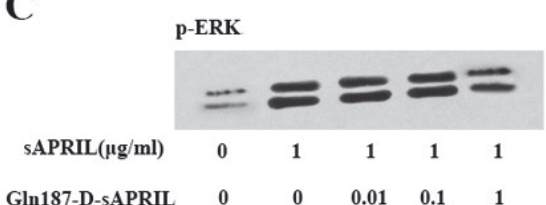

$\begin{array}{llllll}\text { Gln187-D-sAPRIL } & 0 & 0 & 0.01 & 0.1 & 1\end{array}$

$(\mu \mathrm{g} / \mathrm{ml})$

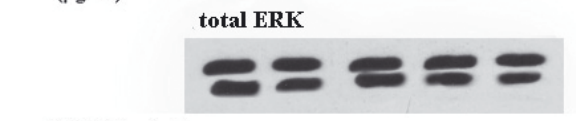

$\begin{array}{llllll}\operatorname{sAPRIL}(\mu \mathrm{g} / \mathrm{ml}) & 0 & 1 & 1 & 1 & 1\end{array}$

$\begin{array}{llllll}\text { Gln187-D-sAPRIL } & 0 & 0 & 0.01 & 0.1 & 1\end{array}$

$(\mu \mathrm{g} / \mathrm{ml})$

E

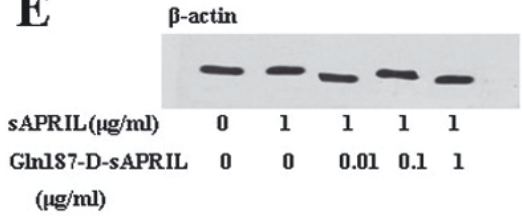

B

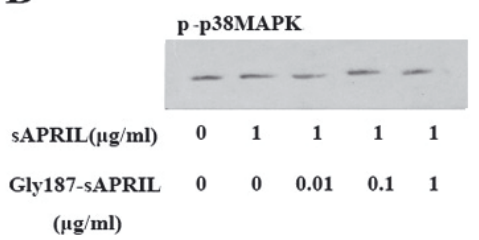

D
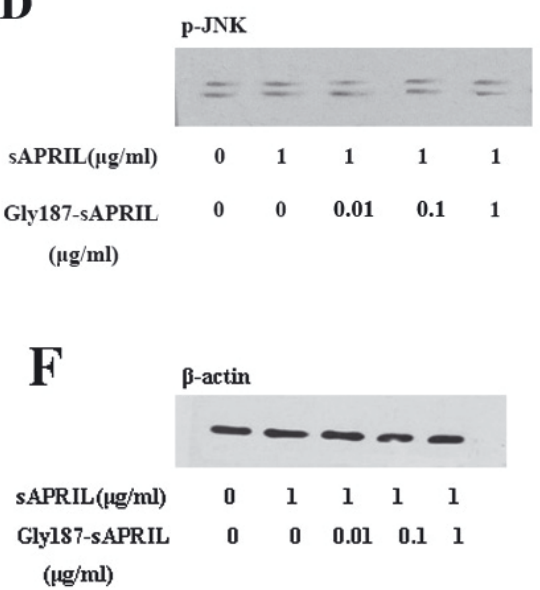

B

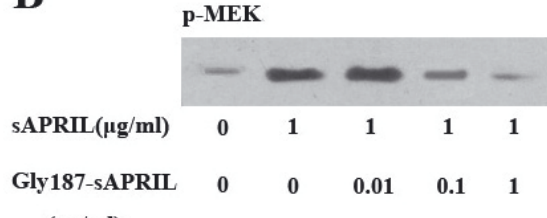

$(\mu \mathrm{g} / \mathrm{ml})$

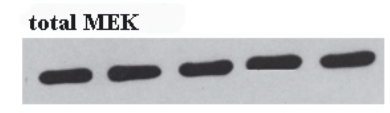

$\begin{array}{cccccc}\text { sAPRIL }(\mu \mathrm{g} / \mathrm{ml}) & 0 & 1 & 1 & 1 & 1 \\ \begin{array}{c}\text { Gly187-sAPRIL } \\ (\mu \mathrm{g} / \mathrm{ml})\end{array} & 0 & 0 & 0.01 & 0.1 & 1\end{array}$

D

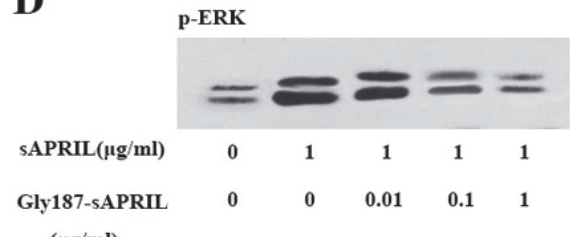

$(\mu \mathrm{g} / \mathrm{ml})$
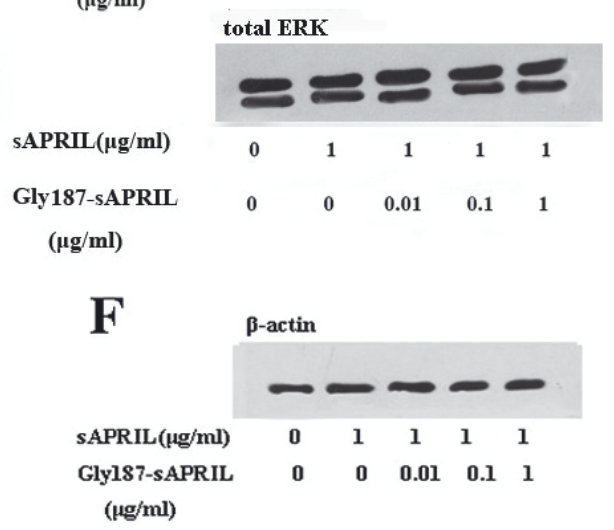

Figure 5. p-p38 MAPK and p-JNK in the signaling of mutant-mediated blocking of sAPRIL-induced proliferation of A549 cells.

A549 cells were treated with various concentrations (0.01, 0.1 or $1 \mu \mathrm{g} / \mathrm{mL}$ ) of Gln187D-sAPRIL or Gly187-sAPRIL in the presence of $1 \mu \mathrm{g} / \mathrm{mL}$ sAPRIL. Thirty minutes later, whole cell proteins were extracted for Western blot. The blots were probed with phospho-specific antibody for p-p38 or p-JNK to determine their phosphorylation. (A) and (B): p-p38 level after challenge with Gln187-DsAPRIL or Gly187-sAPRIL. (C) and (D) p-JNK level after challenge with Gln187-DsAPRIL or Gly187-sAPRIL. (E) and (F) $\beta$-actin was the control.
Figure 6. p-MEK and pERK in the signaling of mutant-mediated blocking of sAPRIL-induced proliferation of A549 cells.

Treatment of A549 cells and Western blot were done as described in Fig. 4 using total MEK- or total ERK- and p-MEK- or p-ERK1/2-specific antibodies. (A) and (B): p-MEK and total MEK after challenge with Gln187-DsAPRIL or Gly187-sAPRIL. (C) and (D): p-ERK and total ERK after challenge with Gln187-D-sAPRIL or Gly187-sAPRIL. (E) and (F) $\beta$-actin was the control. 

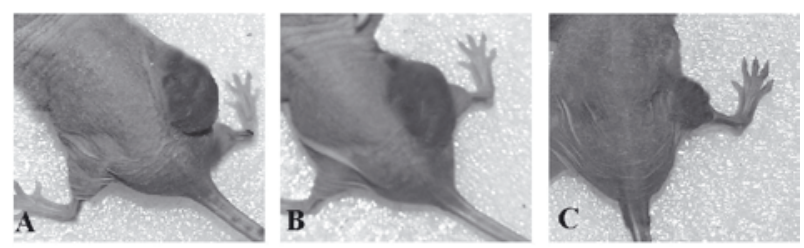

D

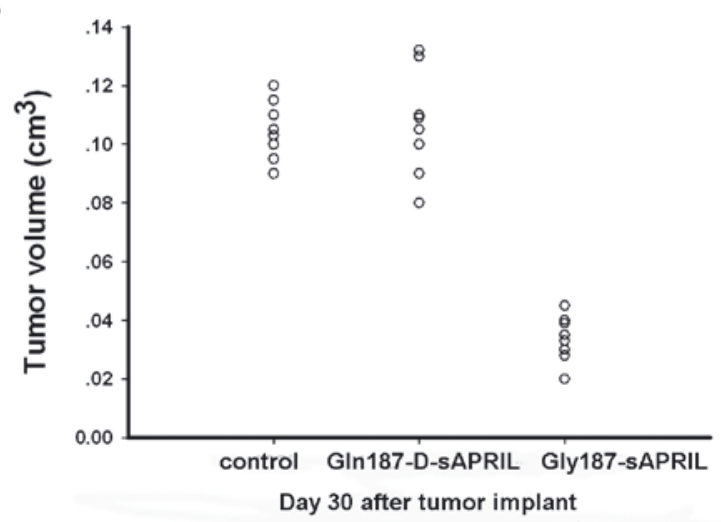

Figure 7. In vivo anti-tumor effect of two sAPRIL mutants.

A549 cells were implanted into nude mice subcutaneously. The animals were injected i.p. with $1 \mathrm{mg} / \mathrm{kg}$ Gly187-DsAPRIL (B) or Gly187-sAPRIL (C) just before tumor cell implantation and every three days thereafter. Mice treated with vehicle served as control (A). Xenograft tumor volumes were measured at 30 days after A549 cell implantation (D) ( $\mathrm{n}=8$ mice/group).

A549 cells with $1 \mu \mathrm{g} / \mathrm{mL}$ sAPRIL in the presence of various concentrations of Gln187-D-sAPRIL or Gly187sAPRIL. As expected, Gly187-sAPRIL completely blocked and Gln187-D-sAPRIL partially blocked the sAPRIL-induced proliferation of A549 cells. These results confirmed that both mutants of Gln187 have an antagonistic or competitive activity (whether strong or weak) against sAPRIL in vitro. This finding also suggests that Gln187 is not required for the binding of sAPRIL to A549 cells but is necessary for its function in inducing tumor cell proliferation.

So far, the signaling pathway responsible for the tumor growth-inducing function of sAPRIL is poorly known. Previous reports have shown that the growth-promoting effects of APRIL on some tumor cells are associated with activation of p38 MAPK signaling (Trabach et al., 2002; Mackay et al., 2003). It is also possible that the other two MAPK signaling pathways, JNK and MEK/ERK, are also involved in the activity of APRIL. To identify the signaling pathway involved in the APRIL-antagonizing effects of its two mutants, we investigated three crucial component of the MAPK pathways: p38, JNK, and MEK/ERK. The results showed that sAPRIL strongly increased the phosphorylation of MEK and, to a lesser extent, of p-ERK but not of p38 and JNK. This stimulating effect could be suppressed by Gln187-DsAPRIL partially and by Gly187-sAPRIL completely.
ERK is the best-studied molecule of the MAPK pathway and is activated by many growth factors and cytokines that are important in driving proliferation and preventing apoptosis in cancers, such as hepatocellular carcinoma, lung cancer, breast cancer, and pancreatic cancer (Ito et al., 1998; Dhillon et al., 2007). In the present study, we found that activation of the MEK/ERK pathway might be involved in sAPRIL-induced A549 cell proliferation and that Gln187 might be a key amino-acid residue for sAPRIL in triggering this signaling. In addition, inhibition of APRILinduced activation of MEK/ERK (but not p38 and JNK) signaling might be one of the mechanisms for the mutant-mediated blocking of sAPRIL-induced proliferation of A549 cancer cells. Previous studies have demonstrated the elevated ERK activation mediated by HSPGs contributes to the overexpression of fibrotic proteins (Rabenstein, 2002; Chen et al., 2008), which to some extent supports our speculation that HSPG expressed on A549 cells might mediate the binding and activity of sAPRIL and its mutants. But to confirm this signal pathway, further investigation is needed.

The results of the in vitro experiments showed that the beneficial anti-tumor effect of the Gly187sAPRIL mutant was much stronger than that of Gln187-D-sAPRIL, and the in vivo experiments confirmed that Gly187-sAPRIL significantly suppressed xenograft tumor growth in nude mice implanted with A549 cells, while Gln187-D-sAPRIL had little effect. We speculate that replacement of Gln187 with Gly can make the recombinant mutant protein more flexible, better refolded for exerting a stronger effect compared with the mutant with deletion of $G \ln 187$. More studies are needed to show whether it is true.

Taken together, we successfully generated two Gln187 mutants of sAPRIL and using in vitro and in vivo assays showed that it is a promising way to developing a novel anti-cancer strategy for the treatment of APRIL-associated tumors.

\section{Acknowledgements}

We thank Dr. Lingfeng Chen and Huiguang Gao for their contribution to this paper.

This work was supported by the Scientific Research Foundation for the Returned Overseas Chinese Scholars, State Education Ministry (to F.H.) and Natural Science Foundation of Chongqing, China (to Y.Z., No. CSTC2006BB5110).

\section{REFERENCES}

Bonci D, Hahne M, Felli N, Peschle C, De-Maria R (2004) Potential role of APRIL as autocrine growth factor for megakaryocytopoiesis. Blood 104: 3169-3172. 
ChenY, Leask A, Abraham DJ, Pala D, Shiwen X, Khan K, Liu S, Carter DE, Wilcox-Adelman S, Goetinck P, Denton CP, Black CM, Pitsillides AA, Sarraf CE, Eastwood M (2008) Heparan sulfate-dependent ERK activation contributes to the overexpression of fibrotic proteins and enhanced contraction by scleroderma fibroblasts. Arthritis Rheu 58: 577-585.

Dhillon AS, Hagan S, Rath O, Kolch W (2007) MAP kinase signalling pathways in cancer. Oncogene 26: 3279-3290.

Gao H, Fu W, Li R, Chen L, Ji Q, Zhang L, Huang G, He F (2006) Expression and purification of a soluble B lymphocyte stimulator mutant modified with the T-helper cell epitope. Biotechnol Lett 28: 1649-1654.

Hahne M, Kataoka T, Schröter M, Hofmann K, Irmler M, Bodmer JL, Schneider P, Bornand T, Holler N, French LE, Sordat B, Rimoldi D, Tschopp J (1998) APRIL, a new ligand of the tumor necrosis factor family, stimulates cell growth. J Exp Med 188: 1185-1190.

Hendriks J, Planelles L, de Jong-Odding J, Hardenberg G, Pals ST, Hahne M, Spaargaren M, Medema JP (2005) Heparan sulfate proteoglycan binding promotes APRIL-induced tumor cell proliferation. Cell Death Differ 12: 637-648.

Ingold K, Zumsteg A, Tardivel A, Huard B, Steiner QG, Cachero TG, Qiang F, Gorelik L, Kalled SL, Acha-Orbea H, Rennert PD, Tschopp J, Schneider P (2005) Identification of proteoglycans as the APRIL-specific binding partners. J Exp Med 201: 1375-1383.

Ito Y, Sasaki Y, Horimoto M, Wada S, Tanaka Y, Kasahara A, Ueki T, Hirano T, Yamamoto H, Fujimoto J, Okamoto E, Hayashi N, Hori M (1998) Activation of mitogenactivated protein kinases/extracellular signal-regulated kinases in human hepatocellular carcinoma. Hepatology 27: 951-958.

Iłzecka J, Iłzecki M (2006) APRIL is increased in serum of patients with brain glioblastoma multiforme. Eur Cytokine Netw 17: 276-280.

Kalled SL, Ambrose C, Hsu YM (2005) The biochemistry and biology of BAFF, APRIL and their receptors. Curr Dir Autoimmun 8: 206-242.

Liu Y, Xu L, Opalka N, Kappler J, Shu HB, Zhang G (2002) Crystal structure of sTALL-1 reveals a virus-like assembly of TNF family ligands. Cell 108: 383-394.

López-Fraga M, Fernández R, Albar JP, Hahne M (2001) Biologically active APRIL is secreted following intracellular processing in the Golgi apparatus by furin convertase. EMBO Rep 2: 945-951.

Mackay F, Ambrose C (2003) The TNF family members BAFF and APRIL: the growing complexity. Cytokine Growth Factor Rev 14: 311-324.

Marsters SA, Yan M, Pitti RM, Haas PE, Dixit VM, Ashkenazi A (2000) Interaction of the TNF homologues BLyS and APRIL with the TNF receptor homologues BCMA and TACI. Curr Biol 10: 785-788.
Medema JP, Planelles-Carazo L, Hardenberg G, Hahne M (2003) The uncertain glory of APRIL. Cell Death Differ 10: $1121-1125$.

Planelles L, Castillo-Gutiérrez S, Medema JP, Morales-Luque A, Merle-Béral H, Hahne M (2007) APRIL but not BLyS serum levels are increased in chronic lymphocytic leukemia: prognostic relevance of APRIL for survival. Haematologica 92: 1284-1285.

Rabenstein DL (2002) Heparin and heparan sulfate: structure and function. Nat Prod Rep 19: 312-331.

Rennert P, Schneider P, Cachero TG, Thompson J, Trabach L, Hertig S, Holler N, Qian F, Mullen C, Strauch K, Browning JL, Ambrose C, Tschopp J (2000) A soluble form of $\mathrm{B}$ cell maturation antigen, a receptor for the tumor necrosis factor family member APRIL, inhibits tumor cell growth. J Exp Med 192: 1677-1683.

Roosnek E, Burjanadze M, Dietrich PY, Matthes T, Passweg J, Huard B (2009) Tumors that look for their springtime in APRIL. Crit Rev Oncol Hematol 2: 91-97.

Roth W, Wagenknecht B, Klumpp A, Naumann U, Hahne M, Tschopp J, Weller M (2001) APRIL, a new member of the tumor necrosis factor family, modulates death ligand-induced apoptosis. Cell Death Differ 8: 403-410.

Schwaller J, Schneider P, Mhawech-Fauceglia P, McKee T, Myit S, Matthes T, Tschopp J, Donze O, Le Gal FA, Huard B (2007) Neutrophil-derived APRIL concentrated in tumor lesions by proteoglycans correlates with human B-cell lymphoma aggressiveness. Blood 109: 331-338.

Stein JV, López-Fraga M, Elustondo FA, Carvalho-Pinto CE, Rodríguez D, Gómez-Caro R, De Jong J, MartínezA C, Medema JP, Hahne M (2002) APRIL modulates B and $\mathrm{T}$ cell immunity. J Clin Invest 109: 1587-1598.

Trabach L, Lugovskoy A, Vlijmen HV, Dejardin E, Kalled SL, Rennert P (2002) APRIL and BAFF are members of a unique subfamily within the TNF family of proteins. Curr Trends Immunol 4: 25-45.

Wallweber HJ, Compaan DM, Starovasnik MA, Hymowitz SG (2004) The crystal structure of a proliferation-inducing ligand, APRIL. J Mol Biol 343: 283-290.

Wingfield PT (1995) Overview of the purification of recombinant proteins produced in Escherichia coli. In Current protocols in protein science. Coligan JE, Dunn BM, Ploegh HL, Speicher DW, Wingfield PT, eds, vol 1, pp 6.1.1-6.1.22, John Wiley and Sons, New York.

Yu G, Boone T, Delaney J, Hawkins N, Kelley M, Ramakrishnan M, McCabe S, Qiu WR, Kornuc M, Xia XZ, Guo J, Stolina M, Boyle WJ, Sarosi I, Hsu H, Senaldi G, Theill LE (2000) APRIL and TALL-I and receptors BCMA and TACI: System for regulating humoral immunity. Nat Immunol 1: 252-256. 